encourage readers to go even further then Holmes in searching for an integrated and coherent developmental psychobiosocial approach relevant to their daily clinical practice. The biological elements emphasise the need to step away from phase-based models of development, be they Piagetian, Kleinian or Eriksonian, and wholeheartedly adopt the developmental pathways approach followed by Bowlby. In that lies a revolution for our field which I hope that readers will ponder over and perhaps espouse.

Crittenden, P. M. (1992a) Quality of attachment in the preschool years. Development and Psychopathology, 4, 209-241.

$(1992 b)$ Treatment of anxious attachment in infancy and early childhood. Development and Psychopathology, 4, 575-602.

KrAEmer, G. W. (1992) A psychobiological theory of attachment. Behavioral and Brain Sciences, 15, 493-541.

MURRAY, L. \& COOPER, P. (1993) Clinical applications of attachment theory and research: change in infant attachment with brief psychotherapy. Journal of Child Psychology and Psychiatry (in press).

TULVING, E. (1985) How many memory systems are there? American Psychologist, 40, 385-398.

WINNICOTt, D. W. (1971) Playing and Reality. Harmondsworth: Penguin (1980).

SIMON R. WILKINSON

Barne-og Ungdomspsykiatrisk Avd. Ullevål Sykehus

0407 Oslo

Norway

SIR: Dr Jeremy Holmes' article was very welcome at a time when the psychotherapies are being questioned and are questioning their place in the treatment of mental disorders.

I would argue that attachment theory does have the potential to form the basis of a 'Bowlbian', thoroughly interpersonal 'school' of psychotherapy developing naturally out of current thinking on object relations theory and out of recent developments in attachment theory.

The idea of an 'attachment dynamic' (Heard \& Lake, BJP, October 1986, 149, 430-438) broadens the concept of attachment as a primary, goal-directed instinct in the human search for well-being. The supportive aspect of attachment (caregiving and protection in childhood, and a haven from threats and life stresses in adulthood) is matched by and is dynamic with a developmental aspect derived from 'playful interaction' in childhood between parent and offspring, and from 'companionable interaction' in adulthood. Stern (1985) emphasises the importance of the latter in infancy for the development of the self. Ego strength and self-esteem are diminished by a failure in the attachment process.
Psychotherapy can be identified by its aims and by its techniques (both infused by its theoretical basis). A Bowlbian therapy might have the aim of providing an experience of secure attachment with its two strands of support and emotional development. The therapist's task would then be to get to know his/her patients, their individual needs and their individual responses to difficulties, to respond appropriately to their different pleasures and woes, and to remain in emotional contact with them through the range of different feeling states. The therapist would thus be aiming to provide a model for intimacy, and to help the patient to give up maladaptive attachment patterns, both overly clingy or overly independent.

Technique would entail the reframing of 'resistance' and the emotionality of 'transference' in terms of insecure attachment (resistance equating with avoidant attachment, and transferance with ambivalent attachment), and would emphasise to patients the naturalness of some expression of separation and of reunion phenomena. It would address the way fear about unreliable and abusive attachment can cause people to focus on specific aspects of a relationship while ignoring other aspects. Using Daniel Stern's terminology, the therapist would work to modulate affect within the relationship by 'attuning' to low and high levels of affect, and by 'purposefully misattuning' to emotions and behaviour in order to broaden the individual's range of emotional responses and develop mastery and understanding of different feeling states. Both experiential and cognitive techniques have an important place in this process.

The emphasis would be on real difficulties in developing a confiding relationship, the disappointment that occurs when the therapist inadvertently makes mistakes, and the way mutual misunderstandings are handled in the therapy. In this way the power relationship of therapy might be minimised and an empowering partnership achieved. The aim of promoting secure and healthy attachment patterns clarifies the need to interpret resistance or defence in the arena of the therapy relationship. Internal object relations in the light of attachment theory refers to past unsuccessful attachment relationships (internal working models) and also to the attempt to repress the attachment instinct or need by calling it bad, shameful, or too exciting or terrifying, or by denying its existence, so creating a false autonomy.

Attachment theory suggests that research into the outcome of dynamic psychotherapy should concentrate more on changes in the nature of attachment in work and in partnerships following therapy. Process research might include the study of the changing attachment between patient and therapist from 
insecure to secure, and the balance between support and exploration as this process develops.

StERN, D. N. (1985) The Interpersonal World of The Infant. New York: Basic Books.

Leeds Community and Mental Health Services

40 Clarendon Road

Leeds LS2 9PJ

\section{Variations on the theme of euthanasia}

SIR: Dr Helme has made an important contribution to the debate on euthanasia (BJP, October 1993, 163, 456-466). The debate will continue with added intensity but certain associated problems, actions and philosophies need to be examined.

There are obvious and forceful arguments for allowing something to be done to relieve an individual of the terror of continuing irreversible pain and other miseries that can affect the body in terminal illness. The worrying thing is that arguments are put forward for killing people who are not necessarily suffering from pain but appear to have miserable, poor quality, meaningless lives. This applies particularly to those labelled as suffering from one of the dementias. It is said that they end up as vegetables, lacking all human feelings or experiences. This is arrogant human stupidity. All of us, until we are dead, experience something of being a human being, and quality of life is not something that others can judge. I am sure that large numbers of victims of dementia enjoy life just as much and perhaps more than many highly intelligent professionals and other pontificators on the subject.

In reality, euthanasia is occurring now in various guises. In many hospitals patients are categorised into three groups: one group must be resuscitated and treated with a maximum of medical ability; the next group are treated, but not so intensely; and the third group are not to be resuscitated and not treated with any vigour. Many doctors are refusing lifesaving treatments to smokers, drinkers and the mentally distressed who take repeated overdoses. Others give opiates to victims of dementia who are not suffering pain or distress themselves but may be causing problems for others. The evidence for the former examples is very well documented, while evidence for the latter is anecdotal but appears widespread.

Present trends must be treated as unacceptable, before they quickly move into the grossly unacceptable with chronic mental illness, chronic physical disability, chronic antisocial behaviour and anything else that upsets the authoritarianism of the silent majority becoming grounds for either covert euthanasia or even overt legal intervention.
There must never be any place for moral or value judgements in medicine. Anyone who makes these kinds of judgements would be better becoming something other than a doctor.

Present trends are very dangerous. All of us should be aware that we, in our turn, could become victims.

\author{
Mental Health Services for Older People \\ Brighton General Hospital \\ Elm Grove \\ Brighton BN2 3EW
}

TONY WHITEHEAD

SIR: Dr Helme's massively comprehensive review (BJP, October 1993, 163, 456-466) of the literature on euthanasia is most impressive. His proposals for establishing Tribunals - to protect mercy-killing doctors from prosecution even more than terminally ill patients from overzealous euthanasiasts - sound thoughtfully organised, but the idea of what could become known as Death Committees would surely be repugnant to many of us, and his scheme skates over such associated practicalities as who should be appointed as 'licensed liquidators' and what should be approved techniques for the despatch of approved applicants or nominees.

Should we allow ourselves to be pressurised to this point by increasingly permissive public opinion? The tiny minority of Hospice patients who are importunate for euthanasia are those with a superadded depression, not those with the most pitiable physical conditions - many of whom still struggle to survive, as is the norm in Nature.

As for patients who have become grossly demented, they are per se incapable of giving valid consent for their own elimination. So might we not need to try to enlighten public opinion, rather than be inveigled into colluding with suicidal states or-expediently and economically - putting distressed or distressing patients out of their beholders' misery?

As a Hospice-engaged psychiatrist, I respect the merciful and idealistic intentions of those who call for the legalisation of euthanasia, but how fully do they understand the psychopathology of 'impatient patients', relatives, carers and not least the doctors who would have to be commissioned to deliberately extinguish residual life?

How many compassionate, rather than powerseeking, productivity-conscious doctors would aspire to become medical 'serial killers'?

\author{
Phyllis Tuckwell Memorial Hospice \\ Waverley Lane, Farnham \\ Surrey GU9 8BL
}

